\title{
A multidimensionalidade da competência em informação num contexto de vulnerabilidade social: narrativas em
}

\section{foco}

\author{
Tânia Regina de Brito \\ Elizete Vieira Vitorino \\ Universidade Federal de Santa Catarina, Programa de Pós-Graduação em Ciência da Informação. \\ Florianópolis, Brasil
}

\section{CASE REPORT}

\begin{abstract}
Resumo
Objetivo. Compreender a multidimensionalidade da competência em informação e da vulnerabilidade social, identificando no projeto Luces para Aprender (LPA) conexões com as dimensões técnica, estética, ética e política da competência em informação. Método. Entrevista narrativa com pessoas ligadas ao Luces para Aprender, projeto da Organização de Estados Ibero-Americanos para a Educação, a Ciência e a Cultura (OEI) e a análise de dados feita sob um enfoque fenomenológico. Estudo bibliográfico acerca da competência em informação e suas dimensões, vulnerabilidade social e assuntos correlatos, realizado em bases de dados nacionais e internacionais por meio do Portal de Periódico da CAPES, sendo consultada também a BRAPCI, que recupera dados de revistas científicas brasileiras e do ENANCIB, assim como dos anais do CBBD. Pesquisa documental a partir da análise de documentos disponibilizados pela OEI. Resultados. A OEI promove ações voltadas ao compromisso e preocupação com questões relacionadas ao comportamento informacional, sendo identificadas nas narrativas conexões entre o LPA e o desenvolvimento da competência em informação nas dimensões técnica, estética, ética e política, baseadas em Vitorino e Piantola (2011). Conclusions. O acesso e uso da informação ficam limitados em regiões sem infraestrutura básica, como o acesso à energia e à internet. No entanto, quando esta barreira é minimamente rompida, as oportunidades que surgem no universo informacional fazem a diferença na vida de sujeitos e comunidades em situação de vulnerabilidade.
\end{abstract}

Palavras-chave

Competência em informação. Dimensões da competência em informação. Mediação da informação. Projeto Luces para Aprender.; Vulnerabilidade social.

\section{The multidimensionality of information literacy in a context of social vulnerability: narratives in} focusAbstract

Objetive. To understand the multidimensionality of information literacy and the social vulnerability, identifying in the Luces para Aprender project (LPA) connections with technical, aesthetic, ethical and political dimensions of information literacy. Method. Narrative interview with people connected to Luces Para Aprender, a project created by Organization of IberoAmerican States (OEI) and data analysis, using the phenomenological search. Bibliographic study about information literacy and its dimensions, social vulnerability and similar subjects, a study that was made based on national and international data from electronic portal of CAPES, consulting also the BRAPCI, a database support that recovers data from Brazilian scientific magazines and the ENANCIB, as well as the annals from CBBD. Documental search obtained through available documents of OEI. Results. The OEI foments actions focused on responsibility and worry about the issues of information behavior, recognizing on these narratives connections between LPA and the development of information literacy in the technical, aesthetic, ethical and political dimensions, based on Vitorino and Piantola (2011). Conclusions. The access and the use of information are restricted for regions with no basic infrastructure, like electricity and internet access. However, when this obstacle is minimized, the opportunities that appear in the informational universe make difference in people's lives and also in vulnerable communities.

\section{Keywords}

Dimensions of information literacy. Information literacy. Luces para Aprender projec.; Mediation information. Social vulnerability. 


\section{Introdução}

Este artigo apresenta os resultados de um estudo sobre a competência em informação e de suas dimensões, a partir de entrevistas narrativas realizadas com pessoas ligadas ao Luces para Aprender (LPA), um projeto da Organização de Estados Ibero-Americanos para a Educação, a Ciência e a Cultura (OEI). Ancorado na sustentabilidade do meio ambiente, na geração de energia por meio da instalação de placas fotovoltaicas, na conectividade, formação docente e fortalecimento comunitário, o projeto LPA visa implementar um programa de melhorias na qualidade da educação, em regiões socialmente vulneráveis, da região ibero-americana.

Num contexto que abrange comunidades rurais e isoladas, estuda-se, portanto, a competência em informação sob a perspectiva da vulnerabilidade social, já que o projeto Luces para Aprender visa atender populações prejudicadas pela falta de acesso à energia e também da internet, ficando com isso, limitadas no acesso e uso da informação.

A competência em informação, assunto recorrente em pesquisas na área da Ciência da Informação, sendo estudada sob diversas perspectivas e em diferentes ambientes, surgiu a partir de um relatório do bibliotecário americano Paul G. Zurkowski em 1974. O relatório abordava sobre a infraestrutura que subsidiava a cena dos serviços de informação, à época, afirmando que a mesma estava sendo vigorosamente influenciada pela tecnologia, cujo desenvolvimento dava-se a todo vapor (ZURKOWSKI, 1974). Desde esse primeiro registro do termo "Information Literacy" (IL) na literatura, ao longo dos anos, o conceito da competência em informação tem sido discutido, revisitado, revisto, aprimorado e a ele acrescentado elementos que visam traduzir ou traçar caminhos que facilitem o "ser competente em informação".

Segundo Dudziak (2008), a competência em informação está relacionada à cidadania e supera atividades de busca, de organização ou do uso de informações. Segundo a autora, competência em informação diz respeito ao porquê desse uso e envolve concepções ideológicas, políticas e/ou ambientais. Está estritamente ligada a uma condição de sustentabilidade social, cultural, ecológica e econômica. Para Belluzzo (2018), a competência em informação ancora-se em princípios que envolvem a aplicação de técnicas ligadas ao comportamento informacional. A competência em informação também pode ser entendida como um processo e constituindo-se de "[...] atividades que objetivam desenvolver o senso crítico das pessoas em relação ao uso da informação" (BELLUZZO; SANTOS; ALMEIDA JÚNIOR, 2018, p. 67).

$\mathrm{Na}$ literatura são identificadas manifestações e declarações em prol da competência em informação, o que demonstra a abrangência e relevância acerca da temática. A Declaração de Alexandria, por exemplo, compreende a competência em informação no cerne do aprendizado ao longo da vida e também como um direito humano básico e promotora da inclusão social em todas as nações (HIGH-LEVEL, 2006). Depois dela, outras foram elaboradas, mundo afora, visando reforçar as principais diretrizes da competência em informação e/ou conclamando profissionais, governos e diversos setores da sociedade a divulgá-la e valorizá-la. Cita-se como exemplo, a declaração de Lyon (2014), em que considera-se o acesso equitativo à informação, como parte do desenvolvimento sustentável a partir de uma estrutura baseada em direitos humanos. O documento reconhece bibliotecas, arquivos, organizações da sociedade civil, líderes comunitários e os meios de comunicação, como intermediários da informação, com a capacidade de contribuir com o desenvolvimento, através da oferta de treinamentos para o desenvolvimento de habilidades que ajudem as pessoas a acessar e a compreender as informações e os serviços mais úteis para elas. (IFLA, 2014)

A vulnerabilidade, assim como a competência em informação, "[...] resguarda uma complexidade própria [...]" (VITORINO, 2018, p. 71), encontrando-se na literatura elementos que confirmam a conexão entre ambas. Alguns dos aspectos em comum relaciona-se com direitos humanos, educação, inclusão e exclusão social.

A competência em informação é um processo que faz parte do contexto da educação, formal e informal, ao passo que as múltiplas vulnerabilidades existentes no meio social - tais como a econômica, social, demográfica, cultural, existencial etc. (TWIGG, 2001; BUSSO, 2001; ARAGÃO, 2011; MARANDOLA JUNIOR e HOGAN, 2006) - podem influenciar o desenvolvimento da mesma. Em virtude das convergências encontradas entre as duas temáticas, caminha-se na direção de compreender que, quem não tem a oportunidade de desenvolver a competência em informação, pode gerar o que Vitorino (2018) tem tratado, em pesquisas recentes: a "vulnerabilidade em informação", já que o conceito proposto pela referida autora, envolve não só a falta, mas o 
excesso de informação, assim como as tensões geradas por um desenvolvimento com prejuízo das dimensões técnica, estética, ética e política.

Compreender a competência em informação por meio de suas dimensões, técnica, estética, ética e política (VITORINO; PIANTOLA, 2011), auxilia os profissionais da informação, no sentido de melhor desenvolvê-la em contextos específicos, como é o caso de comunidades em situação de vulnerabilidade. Tais dimensões, aplicadas à análise das narrativas e da literatura usada nesta pesquisa, contemplam, de uma maneira ampla, o saber fazer, atividade acima de tudo prática (dimensão técnica), a sensibilidade, inovação e transformação (dimensão estética), contemplando virtudes e atitudes para o bem comum (dimensão ética), assim como aspectos relacionados ao campo da mediação e interação com o coletivo (dimensão política). As quatro dimensões, juntas, formam a base sobre as quais sustenta-se a competência em informação (VITORINO; PIANTOLA, 2011), o que concorre para o desenvolvimento integral do comportamento informacional das pessoas, sobretudo as vulneráveis.

Estabelece como questionamento norteador: Como se configuram as dimensões da competência em informação na Organização de Estados Ibero-Americanos para a Educação, a Ciência e a Cultura (OEI) em relação ao projeto Luces para Aprender? Outrossim, define como objetivo compreender a multidimensionalidade da competência em informação e da vulnerabilidade social, identificando no projeto Luces para Aprender (LPA), conexões com as dimensões técnica, estética, ética e política da competência em informação.

\section{Aspectos metodológicos}

Trata-se de um estudo de natureza básica que objetiva trazer contribuições para a área da Ciência da Informação, mais especificamente para o campo da competência em informação num contexto de vulnerabilidade social; é qualitativo pois fornece uma compreensão mais detalhada dos significados e características dos fenômenos revelados pelos sujeitos da pesquisa. Estudos qualitativos, de acordo com Martins $(2004,2007)$ não se preocupam com a generalização, mas sim a amplitude e profundidade, visando uma explicação válida para o estudo.

De caráter exploratório, permite uma familiarização e melhor compreensão do problema, por meio do estudo bibliográfico, envolvendo as temáticas competência em informação, vulnerabilidade social, minorias, e assuntos correlatos. A pesquisa foi realizada entre os meses de dezembro de 2017 a março de 2018, em bases de dados internacionais como a Library and Information Science Abstracts - LISA (ProQuest), Library, Information Science \& Technology Abstracts with full text (EBSCO), Information Science \& Technology Abstracts - ISTA (EBSCO), Web of Science e Scopus, por meio do Portal de Periódicos da CAPES. A base nacional escolhida foi a Base de Dados em Ciência da Informação (BRAPCI), que recupera dados de 57 revistas científicas brasileiras, assim como Encontro Nacional em Pesquisa em Ciência da Informação (ENANCIB), além dos anais do Congresso Brasileiro de Biblioteconomia e Documentação (CBBD). Utilizou-se como palavras-chave, competência em informação e information literacy, associadas a "termos relacionados com a pesquisa", nos idiomas português, inglês e espanhol.

O estudo caracteriza-se ainda como descritivo, sendo feita a descrição das narrativas em associação com a análise de documentos disponibilizados pela OEI, permitindo identificar a sua contribuição histórica e atual, bem como a do projeto Luces para Aprender, para a promoção de uma educação que contemple a competência em informação.

Para a coleta de dados, a técnica utilizada foi a entrevista narrativa, a pesquisa documental e a bibliográfica. Os dados das entrevistas foram analisados com base em Muylaert et al. (2014) e Weller e Zardo (2013), sob enfoque fenomenológico. As entrevistas foram realizadas por vídeo, via Skype e o programa para a gravação dos áudio foi o Aisseesoft Screen Recorder, um software pago.

Foram entrevistadas pessoas ligadas ao projeto Luces para Aprender, envolvendo a sede da OEI em Madri na Espanha, e os escritórios regionais do Uruguai e do Brasil. 


\section{A contribuição histórica e atual da OEl e do Luces para Aprender: em foco a promoção da educação para a competência em informação}

A Organização de Estados Ibero-Americanos para a Educação, a Ciência e a Cultura (OEI) inicia as suas atividades em 1949, resultado de um acordo estabelecido no Primeiro Congresso Ibero-americano de Educação, celebrado entre diversos países em Madri; atuando ao longo de 70 anos para melhorar a qualidade da educação na Ibero-América, especialmente em comunidades vulneráveis.

A Organização promove projetos nos eixos da ciência, da cultura e da educação, este último de interesse do estudo realizado, tendo em vista dele fazer parte o Projeto Luces para Aprender (LPA), que visa levar energia elétrica e a partir daí o acesso à internet a escolas em situação de vulnerabilidade social. (OEI, [2013?], [2017]). Investigou-se o LPA em escolas rurais do Uruguai que receberam o projeto por não possuirem energia elétrica, tendo desta maneira, o acesso à informação facilitado, com melhorias na educação do país, já que está diretamente relacionado com o processo de ensino-aprendizagem.

O Luces para Aprender é um projeto que tem como objetivo implementar as metas de melhoria na qualidade da educação, estabelecidas no documento "Metas Educativas 2021: la educación que queremos para la generación de los Bicentenários", acordado entre os países que fazem parte da OEI, no ano de 2010. Foram estabelecidas 11 metas gerais, 27 específicas, além de 38 indicadores e nível de êxito a ser alcançado pelos países na área da educação. A meta geral $n^{\circ} 7$, por exemplo, aborda sobre o aprendizado ao longo da vida, sendo identificada em todas elas a intenção da OEI em dar atenção a pessoas em condições de vulnerabilidade, tais como os grupos historicamente excluídos, indígenas, os que não tiveram oportunidade de estudar, em situação de pobreza, dentre outros, tais como os alunos de zonas rurais. (OEI, 2010).

Belluzzo e Feres (2015) fazem uma inter-relação entre a competência em informação, redes de conhecimento e as Metas Educativas 2021, afirmando que:

As 'Metas Educativas 2021' focalizam a questão do aprendizado ao longo da vida, como sendo a necessidade de um aprendizado contínuo e ao longo da vida, abrindo possibilidades para avaliar e reconhecer aprendizados realizados por meio de experiências pessoais, no trabalho ou com a vida, incluindo-se mecanismos para a obtenção da informação, participação em redes de aprendizagem e corporativas. (BELUZZO; FERES, 2015, p. 23, grifo do autor).

Pelo histórico de atuação da OEI, junto aos países e comunidades que apresentam diferenças e fragilidades em seus sistemas educacionais, e trabalhando sob a perspectiva de ações que contemplem o aprendizado ao longo da vida, identifica-se entre os compromissos da OEI a preocupação com questões concernentes ao comportamento informacional, conforme trecho retirado do Metas Educativas 2021:

\footnotetext{
Es imprescindible establecer la relación de las TIC con el desarrollo de la capacidad de los alumnos para aprender a aprender, para buscar información de forma selectiva, para tener una posición crítica ante la información disponible en la red, para fomentar los encuentros personales entre los iguales y no solo los virtuales, para ayudar a comprender la realidad multicultural iberoamericana y para fomentar los valores de tolerancia, respeto, solidaridad y justicia. (OEI, 2010, p. 117).
}

Aspectos relacionados com o comportamento informacional também mostram-se contemplados nas falas das narrativas apresentadas neste estudo, havendo reconhecimento da qualidade e alcance do projeto LPA para as comunidades escolares contempladas com o mesmo.

\section{Desenvolvendo a competência em informação em suas múltiplas dimensões: um caminho para minimizar as vulnerabilidades sociais}

O termo dimensão pode ser compreendido sob algumas perspectivas. Na filosofa pode referir-se a "[...] todo plano, grau ou direção no qual se possa efetuar uma investigação ou realizar uma ação.", de acordo com Abbagnano (2007, p. 327). 
Em contexto voltado para a compreensão da dimensão a partir de estudos sobre riscos, Marandola Jr. (2004, p. 328) afirma que "[...] a dimensão é onde os fenômenos ocorrem. A dimensão reflete a própria natureza destes fenômenos."

Por outro lado, em entendimento voltado para o contexto da competência em informação, Vitorino e Piantola (2011) afirmam que dimensão é "[...] uma face, uma parte de um todo que não se mantém sozinha ou sobrevive sem a outra face ou as outras partes - as outras dimensões." A reunião ou união de todas essas partes visam a competência em informação.

Identifica-se na literatura científica a característica de multidimensionalidade tanto nos estudos referentes à vulnerabilidade, quanto dos que tratam da competência em informação, podendo assim, ambas as temáticas, ser estudadas ou analisadas sob perspectivas diversas. Não pretendendo esgotar a temática, algumas dessas dimensionalidades são citadas neste artigo.

Aragão (2011), por exemplo, considera a existência não de uma vulnerabilidade social, mas sim de várias, afirmando que são em geral, cumulativas:

\footnotetext{
As vulnerabilidades sociais que estamos aqui a considerar são: vulnerabilidades etárias (pessoas idosas ou crianças muito novas), vulnerabilidades sociais stricto sensu (pessoas sós, sem família nem redes sociais ou, no outro extremo, famílias muito numerosas), vulnerabilidades económicas (desempregados, pessoas com rendimentos muito baixos e que não tenham meios sucedâneos de sobrevivência, como meios de transporte próprio, segunda habitação, seguros ou acesso a recursos agropecuários), vulnerabilidades pessoais (pessoas doentes, deficientes), vulnerabilidades culturais (analfabetos, pessoas com escolaridade baixa, minorias linguísticas, info-excluídos) e vulnerabilidades resultantes de exclusão social (imigrantes, minorias étnicas). (ARAGÃO, 2011, p. 11).
}

Para Twigg (2001), os pobres são os mais suscetíveis à vulnerabilidade, embora a mesma não restrinja-se à pobreza. O autor afirma que a vulnerabilidade pode ser econômica, social, demográfica, política e psicológica e que essa multidimensionalidade confere-lhe um caráter de complexidade, já que investigar sobre vulnerabilidade tem como pano de fundo a investigação sobre o funcionamento da sociedade humana, sendo as sociedades humanas, complexas. Quanto mais vulnerável em algum aspecto, mais frágil o indivíduo ou grupo se encontra em tal aspecto.

Marangola Junior e Hogan (2006) consideram dimensões múltiplas da vulnerabilidade social, tais como questões temporais, psicológicas, culturais, dentre outras. Durante a realização da pesquisa que originou este artigo, identificou-se a vulnerabilidade em suas dimensões demográfica, espacial, existencial/psicológica e sociocultural, já que envolveu pessoas que moram em áreas rurais do Uruguai, praticamente isoladas. Narrativas apontam que de maio a setembro, uma época chuvosa naquele país, o armazenamento de energia solar cai, já que as placas instaladas com a ajuda do projeto LPA são fotovoltaicas. Assim, a reserva que possuem de energia é direcionada para a geladeira da escola e que conservará os alimentos dos alunos. Sendo a região distante e isolada, não dispõem de serviços públicos de fácil acesso, visitam a família que ficou na cidade (área urbana) de uma a duas vezes por mês. Realidades assim, acabam por gerar sentimentos de isolamento, afetando inclusive o acesso à informação, visto que o fornecimento de energia também fica prejudicado.

Um aspecto recorrente nas leituras sobre vulnerabilidade refere-se à vinculação desta com a informação para a tomada de decisão, já que a temática envolve questões de previsão de risco, dano, perigo. Conforme Thywissen (2006), informações sobre a probabilidade de ocorrências são fundamentais para decisões na gestão de desastres. Ainda de acordo com a autora: " [...] a vulnerabilidade tem muitas dimensões - física (ambiente construído), social, econômico, ambiental, institucional e humano - e muitas delas não são facilmente quantificáveis". (THYWISSEN, 2006, p. 37, tradução nossa).

Diante do exposto, estudar aspectos relacionados às dimensões da competência em informação estabelecendo conexões com a vulnerabilidade social pode ser caminho para a minimização das múltiplas vulnerabilidades encontradas em comunidades. 
Vitorino (2016) reconhece a análise dimensional da competência em informação, revisitando autores (BRUCE, 2000; TILVAWALA, MYERS e DÍAZ ANDRADE, 2009; STEINEROVÁ, 2010, dentre outros) que fazem essa abordagem. A autora afirma que a " [...] 'metacompetência' se faz e se concretiza em dimensões e que é necessário reconhecê-las para melhor realizar estudos teóricos e práticos nesta área." (VITORINO, 2016, p. 3).

Vitorino e Piantola (2011) sistematizaram características das dimensões da competência em informação classificando-as em técnica, estética, ética e política, afirmando que essas dimensões complementam-se, e que devem estar em harmonia, já que juntas favorecem o desenvolvimento da competência em informação. 0 quadro a seguir, elaborado pelas autoras, contém um resumo dessas características.

Quadro 1. Resumo das características das dimensões da competência em informação.

\begin{tabular}{|c|c|c|c|}
\hline Dimensão técnica & Dimensão estética & Dimensão ética & Dimensão política \\
\hline $\begin{array}{l}\text { Meio de ação no } \\
\text { contexto da informação } \\
\text { Consiste nas } \\
\text { habilidades adquiridas } \\
\text { para encontrar, avaliar e } \\
\text { usar a informação de } \\
\text { que precisamos. } \\
\text { Ligada à ideia de que o } \\
\text { indivíduo competente } \\
\text { em informação é aquele } \\
\text { capaz de acessar com } \\
\text { sucesso e dominar as } \\
\text { novas tecnologias }\end{array}$ & $\begin{array}{l}\text { Criatividade sensível. } \\
\text { Capacidade de } \\
\text { compreender, } \\
\text { relacionar, ordenar, } \\
\text { configurar e ressignificar } \\
\text { a informação. } \\
\text { Experiência interior, } \\
\text { individual e única do } \\
\text { sujeito ao lidar com os } \\
\text { conteúdos de } \\
\text { informação e sua } \\
\text { maneira de expressá-la } \\
\text { e agir sobre ela no } \\
\text { âmbito coletivo. }\end{array}$ & $\begin{array}{l}\text { Uso responsável da informação. } \\
\text { Visa à realização do bem } \\
\text { comum. } \\
\text { Relaciona-se a questões de } \\
\text { apropriação e uso da } \\
\text { informação, tais como } \\
\text { propriedade intelectual, direitos } \\
\text { autorais, acesso à informação e } \\
\text { preservação da memória do } \\
\text { mundo. }\end{array}$ & $\begin{array}{l}\text { Exercício da cidadania. } \\
\text { Participação dos indivíduos } \\
\text { nas decisões e nas } \\
\text { transformações referentes à } \\
\text { vida social. } \\
\text { Capacidade de ver além da } \\
\text { superfície do discurso. } \\
\text { Considera que a informação é } \\
\text { produzida a partir de (e em) } \\
\text { um contexto específico. }\end{array}$ \\
\hline
\end{tabular}

Fonte: Vitorino e Piantola (2011, p. 109).

A análise das entrevistas narrativas são consideradas a partir da proposta das dimensões de Vitorino e Piantola (2011) e são priorizadas na elaboração deste artigo. Além disso, encontra voz em Vitorino (2018) quando a autora propõe uma conexão entre a competência em informação e a vulnerabilidade social, já que a primeira apresenta potencial para fazer evoluir e incrementar a metacompetência nas pessoas "[...] a fim de minimizar os efeitos perversos dos riscos e danos aos quais estão sujeitas no que se refere ao acesso à informação." (VITORINO, 2018, p. 74).

\section{Com a palavra, os sujeitos do projeto Luces para Aprender}

O mundo como fenômeno só tem sentido em sua manifestação na vivência. De acordo com Sokolowski (2004), o estudo da experiência humana e dos modos como as coisas se apresentam para nós, em e por meio dessa experiência, é o que define a fenomenologia. Por meio da mesma, além de pensarmos as coisas dadas para nós na experiência, também compreendemos a nós mesmos enquanto as pensamos.

Sob o enfoque da fenomenologia, procurou-se evidenciar as narrativas, propondo a apreensão da realidade, respondendo ao princípio da intencionalidade, "[...] palavra para significar principalmente intenções mentais ou cognitivas, e não práticas. Na fenomenologia, 'intenção' significa a relação de consciência que nós temos com um objeto." (SOKOLOWSKI, 2004, p. 18). 
Embora o foco seja o projeto Luces para Aprender no Uruguai, pelas especificidades da OEI, abarcou-se sujeitos da OEI em Madri, onde está localizada a sede e sujeitos cuja participação seria fundamental para a compreensão de algumas ações da OEI e do LPA, já que possuem a visão administrativa geral, tendo inclusive a experiência de ter participado da concepção do projeto. No Uruguai, a pesquisa envolveu pessoas com visão administrativa regional, participando da coordenação da implantação do projeto naquele país. Contou ainda com a participação de professores, responsáveis pelas atividades com os alunos em sala de aula. Os participantes do Brasil, com visão administrativa regional, ajudaram a compreender alguns elementos e aspectos da abordagem informacional contemplados pelo projeto, já que embora possa sofrer alguma adaptação nos países, existe uma identidade do projeto.

Neste sentido, delineia-se um perfil multidimensional das pessoas que colaboraram com a pesquisa. Além de abranger sujeitos de localidades diferentes (Brasil, Espanha, Uruguai), com visões experenciais distintas, em função dos cargos ou atribuições que exercem. Além disso, a formação dessas pessoas envolve áreas como Ciências Humanas, Ciências Sociais Aplicadas, Linguística, Letras e Artes, Ciências Exatas e da Terra, o que demostra ser uma equipe multidisciplinar, concorrendo para a visão holística, primada pelas e nas ações da OEI, ajudando-a "[...] reflejar la diversidad y heterogeneidad de contextos, conceptos y realidades que caracterizan a estos colectivos". (OEI, 2015b, p. 8).

Os vários atores participantes do projeto LPA dão uma ideia da complexidade que o envolve, o que evidencia-se na narrativa a seguir: "[...] ha sido un proyecto, desde mi punto de vista, complejo, difícil por los contextos diferentes que tienen los países latinoamericanos [...] digamos el proyecto Luces para Aprender partió de la existencia de un problema multisectorial, o sea, agrupaba diferentes niveles y diferentes sectores y pluriactores [...] o sea, de muchos actores involucrados." (INFORMANTE B).

\subsection{Competência em informação facilitando a educação e aprendizagem ao longo da vida de grupos vulneráveis}

O Plano Ibero-Americano de Alfabetização e Aprendizagem ao Longo da Vida (PIALV), acordado em 2014 na cidade do México, visa atender aos princípios e objetivos do Metas Educativas 2021 e substituiu o Plan Iberoamericano de Alfabetización y Educación Básica de Personas Jóvenes y Adultas (PIA), cujos objetivos eram universalizar a alfabetização na Ibero-América, em que os jovens pudessem concluir a educação básica, e dar continuidade a essa formação ao longo da vida. O "novo PIA", ou PIALV, implementou esses objetivos, prevendo oportunidades de aprendizagem ao longo da vida às populações jovens e adultas, para que os mesmos possam dar continuidade às suas trajetórias educacionais e que lhes seja facilitado o treinamento para a vida produtiva e profissional. (OEI, 2014, 2015, 2017).

A aprendizagem permanente é mencionada por Bawden (2002), que aponta a competência em informação como elemento essencial em uma aprendizagem ao longo da vida e componente central da educação formal. A OEI apoia a visão da nova agenda global da Organização das Nações Unidas (ONU) "Educação 2030" que tem como foco a promoção da aprendizagem ao longo da vida, valorizando uma educação inclusiva e equitativa de qualidade. (OEI, 2017).

Mesmo a educação contínua ou aprendizagem ao longo da vida - esta incorporada ao conceito da competência em informação - fazendo parte de uma agenda mundial que não é recente, e da qual a OEI apoia, verificou-se nas narrativas que o termo competência em informação não foi mencionado, mas revela-se com as possibilidades dadas pela internet e pelo acesso à informação: "[...] es como un mundo nuevo para ellos [...]. Ellos cuando adquieren esa posibilidad de internet y de tener como el acceso a la información, cambian como también la manera de dar clases y empiezan a usar la computadora para ver ejemplos de cosas, como ver películas, tiene que ver como se integran al mundo, como empiezan a ver otras posibilidades." (INFORMANTE A).

A alfabetización informacional aparece diretamente relacionada com as tecnologias de informação e comunicação, assim como as Metas Educativas encontram-se relacionadas com o desenvolvimento do projeto LPA, e ambas com as melhorias na educação: "Se habla de TICs acá [...] Recuerdo que el informe que 
realizamos en UY, las metas educativas que tenían que ver con Luces para Aprender, tenían que ver con mejorar la calidad de educación y el currículo escolar." (INFORMANTE A).

O termo alfabetização digital surge nas narrativas, sendo a tecnologia entendida como uma ferramenta na solução de problemas para o dia a dia, uma possibilidade oportunizada pela competência em informação e que diz respeito à habilidade de usar a informação em processos de trabalho e na solução de problemas: "[...] lo que hemos hecho fue un proceso de alfabetización digital [...] entonces consideramos que la tecnología es una herramienta para solucionar esos problemas, por sí mismo no los va a solucionar, sino va a ser un medio para que los docentes o los miembros comunitarios, incluso los mismos estudiantes puedan solucionar mejor sus problemas del día a día [...] Entonces Luces para Aprender desde luego puede ayudar, pero no necesariamente es suficiente, es necesario un acompañamiento, es necesario una buena orientación porque las tecnologías o cierta formación básica no necesariamente puede garantizar que se contribuya a solucionar los problemas [...] " (INFORMANTE B).

O LPA é entendido como o projeto que não só levou a energia elétrica, mas facilitou a inclusão e o acesso de regiões vulneráveis com o mundo da tecnologia, promovendo melhorias na educação. " [...] a gente não estaria levando luz, mas nós estaríamos levando a conectividade que seria a maneira desses alunos da periferia, ou que ficam isolados, ou que ficam mais distantes dos grandes centros, se inserirem [...] Terem um ensino, uma aprendizagem um pouco mais qualificada, a partir dessas tecnologias da informação ligadas à educação." (INFORMANTE C).

O desenvolvimento na aprendizagem, ao longo dos anos, é revelado nas narrativas, estando relacionado ao uso das tecnologias ligadas à informática, não só dos alunos, mas dos próprios professores que tiveram que lidar com a questão da resistência pelo uso das novas tecnologias: "[...] a los niños les gustan mucho más este sistema de trabajo que el trabajo tradicional que teníamos nosotros [...] ellos aprenden más fácilmente y comparten ese aprendizaje con nosotros los docentes. A veces nosotros los docentes nos cuesta un poco más acostumbrarnos al trabajo desde la informática, en un comienzo se dio que nuestro país, cuando era ya con varios años de antigüedad en el trabajo, se negaba a este trabajo desde la informática, cosa que poco a poco se ha ido concertando y con total normalidad, pero costó, costó mucho ese cambio y sin haber duda que sí, los niños aprenden a ser críticos, a buscar la información..." (INFORMANTE E).

O estado de aprendizado ao longo da vida - no sentido de ampliar, enriquecer e diversificar os caminhos que levam à informação, que se faz necessário desde a infância, devendo seguir por toda a vida, em virtude das exigências colocadas pela sociedade da informação - aparece na narrativa de uma das professoras: "Creo que es indispensable que cada niño esté en contacto desde temprana edad con las TIC's, que tengan todos los niños las mismas oportunidades reales para desarrollar su capacidad intelectual para después progresar en la sociedad actual, cuyo eje fundamental hoy es la información [...] Luces para Aprender amplia, diversifica y enriquece esos caminos de llegada a la información que el niño puede tener." (INFORMANTE F).

A parceria que o LPA, por meio da OEI, tem com outros projetos ou instituições deve ser levada em conta, posto que influencia sobremaneira o objetivo de alavancar uma educação de qualidade em país ou comunidade. Na pesquisa realizada, diversas narrativas mencionam diferentes projetos com os quais a Organização se aliou, o que evidencia a perspectiva política, com o fim de alcançar objetivos coletivos, característicos de organizações desta natureza, como é o caso da OEI (SILVA, 2007). Destaca-se o seguinte trecho: "El proyecto fue vinculado directamente con otros organismos del gobierno, con el Plan Ceibal que es un proyecto socioeducativo [...] Bueno lo que les comentaba del plan Ceibal que es un proyecto de gobierno, que ya viene trabajando en el tema de las TICs desde el 2003, lo que hacen ellos para unir esfuerzos para trabajar en conjunto es armar talleres con agrupaciones [...]" (INFORMANTE A).

De uma maneira geral, as narrativas evidenciaram uma experiência em que termos que definem a temática competência em informação não são do domínio das pessoas envolvidas com o LPA, sejam os de visão administrativa geral, regional ou dos professores. Contudo, essas experiências deixam transparecer a essência de questões relacionadas à competência em informação. Tal assertiva é corroborada pelo disposto no Metas Educativas 2021, tendo como foco a promoção de uma educação de qualidade para todos e ao longo de toda a vida, perspectiva coletivamente manifestada ao longo da pesquisa. 


\subsection{Conexões com o desenvolvimento da competência em informação nas dimensões técnica, estética, ética e política}

Por meio das narrativas, e tendo por base a leitura analítica dos principais documentos do eixo educação e do Luces para Aprender da OEl, foram revelados elementos que contemplam a competência em informação, não tendo sido, no entanto, identificada de maneira formal e explícita um programa que a contemple. Dentre os elementos identificados, destacam-se algumas dimensões da competência em informação, dando-se ênfase neste artigo para as suas dimensões técnica, estética, ética e política, baseadas nas características elencadas por Vitorino e Piantola (2011), conforme o quadro 1 constante do capítulo 4.

O conjunto de informações evidenciadas por meio das narrativas, indica que as mesmas são condizentes com a competência em informação, revelando uma relação com atitudes e ações transformadoras, com potencial para a minimização das múltiplas vulnerabilidades a que encontram-se as pessoas de comunidade local, que vivem em zonas rurais e no campo, e que são contempladas com o projeto LPA.

As necessidades informacionais de populações vulneráveis podem encontrar apoio naquela que constitui-se em "[...] componente de emancipação cognitiva dos indivíduos." (RIGHETTO, VITORINO e MURIEL-TORRADO, 2018, p. 84), ou seja, a competência em informação.

Acredita-se, que, por meio da identificação das dimensões - técnica, estética, ética e política - da competência em informação (conforme quadros 2, 3, 4 e 5), seja possível compreender a configuração das forças motrizes que aumentam ou diminuem a vulnerabilidade em informação, especialmente nas comunidades atendidas pelo projeto LPA. E a partir daí, ser possível, argumentar em favor de um programa ou políticas em voltadas para a competência em informação, sistematizando-a como processo essencial dentro dos contextos educacionais, neste caso, no ibero-americano.

O quadro 2 apresenta trechos de narrativas conectadas com a dimensão técnica da competência em informação, destacando-se as características relacionadas com o meio de ação no contexto da informação, habilidades adquiridas no processo de satisfação das necessidades informacionais e a competência em informação relacionada com o acesso e domínio das tecnologias.

Quadro 2. Narrativas conectadas com a dimensão técnica da competência em informação.

Narrativas conectadas com a dimensão técnica* da competência em informação

\begin{tabular}{|c|c|c|}
\hline $\begin{array}{l}\text { Meio de ação no contexto da } \\
\text { informação }\end{array}$ & $\begin{array}{l}\text { Habilidades adquiridas para } \\
\text { encontrar, avaliar e usar a } \\
\text { informação de que precisamos }\end{array}$ & $\begin{array}{l}\text { Competência em informação } \\
\text { entendida como a capacidade de } \\
\text { acessar com sucesso e dominar } \\
\text { as novas tecnologias }\end{array}$ \\
\hline $\begin{array}{l}\text { "[...] otra particularidad que hay es que } \\
\text { muchas escuelas tenían computadora } \\
\text { portátil, pero no tenían luz. Entonces, no } \\
\text { tenían forma de cargar su computadora, } \\
\text { no había forma de acceder a internet, } \\
\text { pero sí tenían el aparato, tenían como la } \\
\text { herramienta. Tampoco es que tenían } \\
\text { formación, ni los docentes ni los niños } \\
\text { en cómo utilizarla." (INFORMANTE A). }\end{array}$ & $\begin{array}{l}{[\ldots] \text { los niños aprenden a ser críticos, a }} \\
\text { buscar la información, a ser selectivos, } \\
\text { comparten la información, ellos } \\
\text { conocen que medio usar para que sea } \\
\text { más rápida essa información, sea e- } \\
\text { mail, sea otras plataformas... } \\
\text { (INFORMANTE E). }\end{array}$ & $\begin{array}{l}\text { [...] podía tener un computador y } \\
\text { yo también pero si no sabemos } \\
\text { cómo usarlo a lo mejor nunca se } \\
\text { hubiera podido establecer esta } \\
\text { comunicación, es como para } \\
\text { graficar un poco a otra escala } \\
\text { como estas comunidades o como } \\
\text { estas escuelas pueden aprovechar } \\
\text { los medios técnicos o tecnológicos } \\
\text { que pueden tener. (INFORMANTE } \\
\text { B). }\end{array}$ \\
\hline
\end{tabular}

*As categorias estão baseadas em Vitorino e Piantola (2011), onde as autoras apresentam um resumo das características das dimensões da competência em informação.

Fonte: Dados obtidos por meio das narrativas 
O meio de ação no contexto da informação revela tendência das atividades relacionadas às novas tecnologias, e num nível de entendimento de que o acesso à energia e internet são a porta para um melhor desenvolvimento das atividades de ensino aprendizagem. Há indícios de que o "saber fazer" faz parte da prática pedagógica. A chegada do LPA, por sua vez, possibilitou aos participantes expandir suas atividades, muitas delas ligadas à dimensão técnica da competência em informação.

No Uruguai, a formação tanto dos professores quanto dos alunos, é contínua e oportunizada pelo Plan Ceibal, um plano de inclusão e igualdade de oportunidades, ligado à Fundación Ceibal, que visa apoiar com tecnologias as políticas educativas uruguaias. A Fundación Ceibal "[...] é uma instituição que promove, apoia e produz pesquisas de excelência no campo da educação e tecnologia, na busca do desenvolvimento e uso do conhecimento científico". (PLAN CEIBAL, 2018, tradução nossa). A parceria entre o LPA e o Plan Ceibal é discurso recorrente nas narrativas, tanto dos participantes com a visão administrativa quanto pelo manifestado pelos professores.

Como foram entrevistados sujeitos com visões diferentes, administrativa geral, regional e professores, pode-se evidenciar uma dimensão técnica em todos os níveis. Por parte da OEI, com o seu aparato de especialidade na área da educação, o que se evidencia são as suas ações técnicas voltadas para comunidades vulneráveis e para os próprios órgãos com quem estabelece parcerias. Já quanto aos professores, a preocupação se dá com relação às habilidades adquiridas para lidar com diversas esferas e atitudes no uso da informação. E aí, fica evidente o quão fundamental é o Plan Ceibal, tendo sido mencionada, inclusive, a sua biblioteca digital. Também evidencia-se que em virtude do LPA, ampliou-se a dimensão técnica relacionada às habilidades básicas para acessar informações, tendo sido manifestada inclusive a segurança relacionada à internet.

Quanto à dimensão estética, o quadro 3 apresenta trechos de algumas narrativas que a contempla. São considerados aspectos como criatividade sensível, a capacidade de compreender e ressignificar a informação, bem como elementos que revelam a experiência interior e individual das pessoas em lidar com os conteúdos informacionais, agindo sob uma perspectiva coletiva.

Revela-se, por meio das narrativas, que a chegada do LPA contribuiu para que a comunidade pudesse se sentir conectada com o mundo, oferecendo-Ihes melhorias em suas ações na busca por soluções de problemas.

Quadro 3. Narrativas conectadas com a dimensão estética da competência em informação.

Narrativas conectadas com a dimensão estética* da competência em informação

\begin{tabular}{|c|c|c|}
\hline Criatividade sensível & $\begin{array}{l}\text { Capacidade de compreender, } \\
\text { relacionar, configurar e ressignificar } \\
\text { a informação }\end{array}$ & $\begin{array}{l}\text { Experiência interior, individual e } \\
\text { única do sujeito ao lidar com os } \\
\text { conteúdos de informação e sua } \\
\text { maneira de expressá-la e agir } \\
\text { sobre ela no âmbito coletivo }\end{array}$ \\
\hline $\begin{array}{l}\text { Yo creo que en primer lugar, en acceder } \\
\text { a la [búsqueta de soluciones a los } \\
\text { problemas], a poder ver que está } \\
\text { pasando dentro de las comunidades, en } \\
\text { poder trabajar en red, en poder eso, } \\
\text { comunicarse en red, en investigar qué } \\
\text { está pasando en el resto del mundo, no } \\
\text { es aislado.(INFORMANTE A). }\end{array}$ & $\begin{array}{l}\text { Una vez al año se realiza en Minas un } \\
\text { encuentro que se llama la Feria Ceibal, } \\
\text { donde podemos mostrar todo lo que } \\
\text { aprendimos utilizando la tecnología, } \\
\text { ese instan es un momento } \\
\text { enriquecedor porque podemos ver } \\
\text { otras iniciativas y aprender de ese } \\
\text { intercambio que se genera, en este } \\
\text { momento tenemos pensado participar } \\
\text { en un club de arte llevado adelante por } \\
\text { la dirección sectorial de integración } \\
\text { educativa y siempre teniendo em } \\
\text { cuenta las posibilidades que nos } \\
\text { presentan. (INFORMANTE F). }\end{array}$ & $\begin{array}{l}\text { [...] ele [o aluno] se interessa mais } \\
\text { fácil }[\ldots] \text { eles se sentindo } \\
\text { empoderados com aquela } \\
\text { informação, isso aí motivou muito } \\
\text { mais os alunos a irem pra escola, a } \\
\text { querer aprender a fazer atividades } \\
\text { que não faziam até então. Que era } \\
\text { só ali no quadro-negro. } \\
\text { (INFORMANTE C). }\end{array}$ \\
\hline
\end{tabular}

*As categorias estão baseadas em Vitorino e Piantola (2011), onde as autoras apresentam um resumo das 
características das dimensões da competência em informação.

Fonte: Dados obtidos por meio das narrativas

A criatividade sensível, exemplificada com trecho da narrativa no quadro 3, indica que a comunidade já não se vê totalmente isolada, embora permaneça a condição de vulnerabilidade geográfica. Contudo, mesmo com limitações, às pessoas é dada a possibilidade de saber o que se passa além da comunidade em que vivem, abrangendo outras cidades ao redor do mundo. Isso faz emergir outras referências para solucionar os seus próprios problemas.

O ressignificar a informação também está presente em algumas narrativas, como a pertinente ao encontro, na modalidade de feira, em que os professores revelam que aprendem com outras inciativas, havendo troca de informações e propostas pedagógicas. No ensino-aprendizagem, as práticas informacionais são enriquecidas com o trabalho fora da sala de aula, encontrando na realidade, uma compreensão diferente do que estão pesquisando via internet. Assim, podem fazer a relação entre informação disponibilizada em mundo virtual e mundo real.

A OEI montou uma espécie de livreto a fim de registrar os testemunhos de pessoas que fazem parte de escolas contempladas e beneficiadas com o LPA. Tal ação deixa transparecer elementos ligados à dimensão estética, já que envolvem e revelam a experiência interior dessas pessoas. Ou seja, o que significou e de que forma a vida da comunidade e dos sujeitos foi marcada, com e por meio da conectividade.

Na comunidade, o aumento do interesse em aprender, por parte dos alunos, é revelado por professores, o que parece ser compensador e reconfortante para os profissionais em sala de aula, já que todos se mostram mais motivados, inclusive o próprio professor. Apresenta-se ainda o fator transformação social, que a experiência interior e individual acaba gerando na comunidade em que vivem essas pessoas. Falam com emoção e orgulho quando se referem às melhorias proporcionadas, em especial nas práticas em sala de aula e entorno da escola.

O quadro 4, por sua vez, traz trechos de narrativas conectadas com a dimensão ética da competência em informação. São exemplificados elementos que dizem respeito ao uso responsável da informação, que visa à realização do bem comum e questões relacionadas à apropriação e uso da informação.

Quadro 4. Narrativas conectadas com a dimensão ética da competência em informação.

\begin{tabular}{|c|c|c|}
\hline \multicolumn{3}{|c|}{ Narrativas conectadas com a dimensão ética* da competência em informação } \\
\hline Uso responsável da informação & Visa à realização do bem comum & $\begin{array}{l}\text { Relaciona-se a questões de } \\
\text { apropriação e uso da informação }\end{array}$ \\
\hline $\begin{array}{l}\text { [...] no todo se puede reducir al uso de } \\
\text { un computador, porque incluso sin } \\
\text { conexión en internet puedes estimular el } \\
\text { conocimiento, la búsqueda de } \\
\text { información y demás, lo único es que } \\
\text { LPA pone en valor que si estos recursos } \\
\text { de tecnología no se usan acompañados } \\
\text { con una formación docente adecuada } \\
\text { puede quedar en nada. (INFORMANTE } \\
\text { B). }\end{array}$ & $\begin{array}{l}\text { Como cuarto componente está el } \\
\text { fortalecimiento comunitario. Somos } \\
\text { conscientes que Luces sin la } \\
\text { comunidad y el contexto en el que se } \\
\text { inserta la escuela no tiene sentido [...] } \\
\text { otro componente que es la } \\
\text { sostenibilidad, que es básicamente } \\
\text { que todo lo que hemos hecho se } \\
\text { pueda prolongar en el tiempo, no } \\
\text { solamente una sostenibilidad } \\
\text { económica sino todas las capacidades } \\
\text { instaladas en los ministerios, en las } \\
\text { comunidades, pues que se pueda } \\
\text { prolongar en el tiempo. (INFORMANTE } \\
\text { B). }\end{array}$ & $\begin{array}{l}\text { [...] en Uruguay con todo lo que } \\
\text { tiene relacionado al } \\
\text { empoderamiento del género, ahora } \\
\text { el } 26 \text { de abril se conmemora el dia } \\
\text { internacional de las niñas en las } \\
\text { tecnologías de la información y la } \\
\text { comunicación, que las niñas } \\
\text { tengan conocimiento que ese } \\
\text { ámbito digital en el cual } \\
\text { actualmente, según los estudios, } \\
\text { está ocupado por } 80 \% \text { del género } \\
\text { masculino, que las niñas empiecen } \\
\text { a concientizar sobre eso para } \\
\text { poder cambiar es fundamental, y } \\
\text { es a través del acceso a la } \\
\text { información que ellas pueden ser }\end{array}$ \\
\hline
\end{tabular}




\begin{tabular}{l|l|l}
\hline & & $\begin{array}{l}\text { protagonistas de esse cambio. } \\
\text { (INFORMANTE F). }\end{array}$ \\
\hline${ }^{*}$ As categorias estão baseadas em Vitorino e Piantola (2011), onde as autoras apresentam um resumo das \\
características das dimensões da competência em informação.
\end{tabular}

Fonte: Dados obtidos por meio das narrativas

A formação docente está relacionada com a dimensão ética da competência em informação, na medida em que revela preocupação com a comunidade que será envolvida. O projeto LPA não se trata apenas de facilitar o acesso à internet e doar computadores. É preciso um aproveitamento adequado de todos esses recursos, por parte dos professores e alunos. Sem isso, não existe possibilidade de que as vulnerabilidades possam ser minimizadas.

Revela-se ainda o sentimento, entre os entrevistados, de que o LPA visa à realização do bem comum. Além de usar toda a experiência em educação - e tudo o que isso envolve - a condição técnica especializada da OEI, a sensibilidade em tirar da pobreza - por meio da educação - comunidades isoladas e vulneráveis, reveste-lhe, e as suas ações, de um viés ético. O que é reforçado por um dos pilares do projeto que é a sustentabilidade, seja ela econômica ou técnica, de continuidade do projeto.

O bem comum, embutido na intenção de equidade educacional, também é trabalhado em sala de aula com valores comunitários e que podem ser revertidos em bem-estar à comunidade, tais como a conscientização em relação à economia de água e energia, e preocupação com a conservação da limpeza, por exemplo. As ações acabam envolvendo ainda mais os pais no dia a dia da escola porque veem a alegria em seus filhos, sendo eles motivados a também aprender e participar ativamente das atividades das escolas.

Ressalta-se ainda que a apropriação e uso da informação é revelada quando professor menciona a questão de empoderamento de gênero, já que no Uruguai existe um dia reservado a incentivar as meninas no uso das TIC e tal fato é valorizado pelo professor em sala de aula. Apresentam-se por meio das narrativas, diversas ações e atividades, nas quais os alunos são estimulados a vivenciar o que obtiveram por meio da teoria, apropriando-se assim, das informações para o bem da coletividade, e consequentemente, do seu próprio bem.

Finalmente, apresentam-se trechos de narrativas que se conectam com a dimensão política da competência em informação. A natureza da OEI, que é uma organização governamental, e a configuração do projeto LPA que abarca atores de diversos segmentos, contribuem para seja uma dimensão sempre presente nas falas. No quadro 5, algumas narrativas exemplificam elementos envolvendo o exercício da cidadania, capacidade de ver além da superfície do discurso, assim como a consideração de que a informação é produzida a partir de um contexto específico.

Quadro 5. Narrativas conectadas com a dimensão política da competência em informação.

\begin{tabular}{|c|c|c|}
\hline \multicolumn{3}{|c|}{ Narrativas conectadas com a dimensão política* da competência em informação } \\
\hline $\begin{array}{l}\text { Exercício da cidadania e participação } \\
\text { dos indivíduos nas decisões e } \\
\text { transformações da vida social }\end{array}$ & $\begin{array}{l}\text { Capacidade de ver além da } \\
\text { superfície do discurso }\end{array}$ & $\begin{array}{l}\text { Considera que a informação é } \\
\text { produzida a partir de (e em) um } \\
\text { contexto específico }\end{array}$ \\
\hline $\begin{array}{l}\text { Las escuelas rurales en UY se } \\
\text { organizan mucho a través de las } \\
\text { comisiones de fomento [...]. La comisión } \\
\text { de fomento son un grupo de padres. El } \\
\text { maestro de la escuela rural y los padres } \\
\text { son los que, básicamente los que, como } \\
\text { no llegan muchos recursos, están } \\
\text { empobrecidos, no llegan a alcanzar, la } \\
\text { comisión de fomento lo que hace es } \\
\text { trabajar en pró de la escuela, en buscar } \\
\text { recursos, esto es armar fiestas, sorteos, } \\
\text { bailes, hacen cosas para que entren }\end{array}$ & $\begin{array}{l}\text { [...] o projeto demorou um pouco pra } \\
\text { iniciar porque teve toda uma parte } \\
\text { política de convencimento das } \\
\text { secretarias de educação, pra primeiro } \\
\text { lá, e depois a Universidade Federal do } \\
\text { Ceará... Então são um conjunto de } \\
\text { ações, de entes políticos que a gente } \\
\text { teve que fazer antes de iniciar... } \\
\text { (INFORMANTE C). } \\
\text { A gente trabalha com projeto de } \\
\text { cooperação internacional... Qual que é } \\
\text { o papel do organismo internacional? É }\end{array}$ & $\begin{array}{l}\text { [...] la luz eléctrica ha potenciado } \\
\text { el rol de la escuela como agente } \\
\text { socializador, hacemos más } \\
\text { reuniones, más talleres, contamos } \\
\text { con un horario más flexible y } \\
\text { disponible, ya que no debemos } \\
\text { restringirnos a un horario tan } \\
\text { agotado, solo a las horas luz... se } \\
\text { puede acceder a proponer } \\
\text { reuniones y talleres en horas en la } \\
\text { tarde que es cuando las personas } \\
\text { regresan a su casa, la mayor parte }\end{array}$ \\
\hline
\end{tabular}




\begin{tabular}{|c|c|c|}
\hline $\begin{array}{l}\text { mas recursos en las escuelas y para } \\
\text { poder mantenernos, o para poder } \\
\text { comprar cosas que hacen falta en las } \\
\text { escuelas. Entonces en este sentido, me } \\
\text { parece que fortaleció eso de poder } \\
\text { reunirse... (INFORMANTE A). }\end{array}$ & $\begin{array}{l}\text { desenvolver projetos pilotos, é } \\
\text { desenvolver projetos, em temáticas } \\
\text { variadas, é testar, ver se dá certo, para } \\
\text { isso se transformar numa política } \\
\text { pública [...] a gente desenvolve peças, } \\
\text { políticas públicas para eles } \\
\text { executarem. (INFORMANTE C). }\end{array}$ & $\begin{array}{l}\text { de las personas trabajan en el } \\
\text { campo. (INFORMANTE F). }\end{array}$ \\
\hline
\end{tabular}

*As categorias estão baseadas em Vitorino e Piantola (2011), onde as autoras apresentam um resumo das características das dimensões da competência em informação.

Fonte: Dados obtidos por meio das narrativas

Como não existe presença efetiva do Estado, há ocasiões em que os indivíduos da comunidade reúnem-se para suprir necessidades, como o revelado pelo Participante A, organizando eventos para angariar fundos a fim de comprar insumos que faltam à escola. O LPA, ao que foi expresso, veio fortalecer esta dinâmica.

Outro aspecto revelado por meio das narrativas foi a capacidade que se requer ao lidar com um projeto de tamanha complexidade. São diversos atores e há a necessidade que se traduza essa complexidade de informações, aos envolvidos de diversos níveis, desde um chefe de estado a um membro da comunidade que se encontra em condições de múltiplas vulnerabilidades. Foi o que se considerou "ver além da superfície do discurso", percebido apenas em narrativas de sujeitos ligados à visão administrativa, geral ou regional. Entendese que o poder de convencimento para levar um projeto desta natureza a qualquer comunidade, requer conhecimento apurado em áreas diversas, raciocínio lógico, boas práticas de comunicação, pensamento reflexivo, para citar alguns.

Não foram reveladas em narrativas dos professores, atividades práticas em sala de aula em que se observasse o desenvolvimento desta atitude (ver além do discurso), o que certamente é fruto de um pensamento crítico. Tal criticidade alimenta pensamentos cada vez mais apurados. Juntas, as quatro dimensões focadas neste artigo, interligadas entre si, promovem a capacidade de entender e ir além do que se apresenta na realidade, num âmbito informacional. $\mathrm{O}$ fato dos alunos mostrarem-se motivados a aprender, constitui-se apenas um dos elementos para o desenvolvimento da competência em informação. Como já foi mencionado, não existe um "programa" na OEI voltado para a competência em informação, mas a motivação faz-se necessária a qualquer atividade de aprendizado, em especial o aprender a aprender e o aprendizado ao longo da vida.

Como já mencionado, o LPA foi criado para ser desenvolvido em contexto específico, ou seja, com as comunidades vulneráveis, de zonas rurais. Portanto, essa questão da dinâmica do campo, há que ser levada em conta. Onde não tem energia, ou o acesso à mesma não seja tão fácil, as atividades do dia a dia, giram em torno de tal realidade e de tal dificuldade.

\subsection{Competência em informação como elemento mediador da democratização da informação: minimizando vulnerabilidades}

A democratização da informação torna-se imprescindível para que as pessoas possam exercer a cidadania. Além disso, a participação na vida em sociedade é guiada pelas condições de acesso e uso de informações de qualidade, o que pode minimizar as diversas vulnerabilidades a que as pessoas estão sujeitas, em especial, a vulnerabilidade social. Para tal realidade, contribui a competência em informação, ambientada num contexto da educação, seja ela formal ou informal.

Identifica-se em diversas passagens das narrativas elementos de minimização da vulnerabilidade social, mostrando a realidade em que vivem as comunidades ibero-americanas e a diferença que o projeto LPA proporcionou na vida dessas pessoas. As narrativas revelam o que precisa ser fortalecido dentro das políticas de educação, ao mesmo tempo em que evidenciam o que já foi, e o que precisa ser desenvolvido em termos de minimização das vulnerabilidades sociais por meio da mediação e da educação e da competência em informação.

Há relatos sobre a impossibilidade do acesso à internet para o cumprimento, em casa, de atividades complementares à prática pedagógica, como tarefas escolares ou pesquisas de dependam de um computador 
com acesso à internet:" En el caso de la zona rural, se dificulta más para, por ejemplo, mandar tareas como yo les explicaba después. Generalmente en los lugares rurales no hay acceso al internet, entonces sí se puede trabajar de forma áulica y que cada niño pueda cumplir con su tarea, pero ya mandar tareas domiciliarias, por ejemplo, basado en la tecnología de la información es más difícil por que los lugares rurales generalmente no tienen acceso al internet." (INFORMANTE E)

A situação conforme revelada no parágrafo anterior, expõe às multiplicas vulnerabilidades a que estão sujeitos: como a espacial, em virtude das dificuldades geográficas; cultural porque o desenvolvimento cognitivo e de aprendizagem ficam comprometidos e limitados com a escassez de recursos didáticos, prejudicando assim a educação e o acesso à informação, condições fundamentais para que minimizem os efeitos maléficos desta realidade.

A OEI trabalha para minimizar as vulnerabilidades, oferecendo projetos que contemplem a equidade educativa, ampliando o acesso à educação e promovendo a inclusão social, conforme trecho da narrativa: "[...] entonces digamos que esa era parte de su complejidad pero al mismo tiempo parte de su riqueza, luego también LPA confirmó el valor social de esta iniciativa porque también respondía a zonas que estaban completamente olvidadas o por su mismo aislamiento geográfico, lo que hizo el proyecto también fue visibilizarlas." (INFORMANTE B). Assim, o projeto Luces para Aprender passa a ser o elo entre a realidade local e o resto do mundo, já que as cidades que recebem o projeto, "[...] muitas vezes são pequenas, isoladas, muito distante da capital [...] E eles eram privados muita vezes disso [...]" (INFORMANTE C).

A construção de uma sociedade democrática pressupõe o estabelecimento de ações democráticas concretas em todos os espaços da sociedade, em especial os ambientes de interação social, sobretudo nos contextos formais e informais de educação. A competência em informação deve ser um dos elementos de composição para uma construção sólida e resistente, o ingrediente básico que deverá capacitar a humanidade para o domínio do seu desenvolvimento sustentável, livre da pobreza, responsável pela compreensão de si mesmo e acima de tudo, do próximo.

Afirma-se que a perspectiva mediadora da OEI quanto à democratização da informação se faz presente, tendo em vista, conforme assinala Silva et al. (2007) que entre as ações de Organizações desta natureza, a mediação está presente, sendo no nosso entendimento, condição sine qua non, o que pode ser constado em trecho da descrição do Programa de lectura y bibliotecas, que consta no Metas Educativas 2021:

Para impulsar este programa se quiere favorecer una estrecha colaboración con las administraciones educativas y culturales de forma conjunta, en los niveles estatal, provincial y municipal, que haga posible crear y fortalecer redes de lectura pública y escolar en colaboración.

Pero la cooperación deberá ir más allá de la imprescindible implicación de los ministerios de Educación y Cultura; se habrá de buscar el apoyo de la sociedad civil, de editores, libreros, asociaciones, fundaciones, universidades y otros organismos. El conjunto del sector de la lectura, el libro y las bibliotecas habrá de ser aliado de primer orden para lograr los objetivos que se proponen. (OEI, 2010, p. 242).

Se pensarmos o trecho do Metas Educativas 2021 supracitado, na perspectiva do que afirma Gomes (2014), entende-se que a mediação dá-se em dimensões dialógicas, estéticas, formativas e éticas. A autora afirma que o protagonismo social é objetivo implícito da mediação da informação. Sendo assim, a OEl que trabalha no sentido de promover um currículo voltado para competências básicas, sensíveis aos sistemas de informação e de acesso ao conhecimento, com larga experiência na área de educação, assume papel político no processo da democratização da informação.

Baseado em Gomes (2014, p. 55) que instiga a "[...] desvelar toda a riqueza mediadora do fazer informacional em todas as suas instâncias", faz-se um exercício de sensibilidade para compreender nas palavras dos professores do Luces para Aprender, elementos que desvelam como os participantes, envolvidos no processo de mediação da informação "[...] sentem-se acolhidos e reconhecidos como participantes ativos, como protagonistas da informação." (GOMES, 2014, p. 52). São revelações sem consciência dos conceitos ou abordagens técnicas, seja em relação à competência em informação, seja sobre a mediação da informação. Mas que se encontra presente no cotidiano dessas pessoas, que estão envolvidas diretamente com os alunos em sala de aula: "En cuanto las propuestas pedagógicas, se han enriquecido notablemente. Todos los 
recursos que nos ministra la red están a disposición de los alumnos cuando antes no era así, para abordar un contenido."(INFORMANTE F, grifo nosso).

Ao caracterizar, por meio da literatura e a partir das entrevistas narrativas, a competência em informação como mediadora da democratização da informação, fica evidenciado que, como sustenta Belluzzo, Santos e Almeida Júnior (2014), a competência em informação e a mediação da informação são indissociáveis. Ambas são "[...] ações de interferência realizadas por mediadores no processo de ensino-aprendizagem de competências e habilidades informacionais [...]" (BELLUZZO, SANTOS, ALMEIDA JUNIOR, 2014, p. 67).

\section{Considerações finais}

Com o objetivo de compreender a multidimensionalidade da competência em informação e da vulnerabilidade social, identificando no projeto Luces para Aprender (LPA) conexões com as dimensões técnica, estética, ética e política da competência em informação, procurou-se identificar a competência em informação como facilitadora para a promoção da educação e aprendizagem ao longo da vida de grupos sociais vulneráveis das regiões ibero-americanas.

Apesar de não ter sido identificado o termo competência em informação, e ele não tenha sido mencionado pelas pessoas que participaram da pesquisa, a análise das narrativas aponta conexões com as dimensões daquela. Evidenciam-se também ações que visam minimizar as vulnerabilidades de comunidades que não possuem uma infraestrutura básica como o acesso à energia e à internet, ficando assim limitados, o acesso e uso da informação.

Mesmo com referência ao universo informacional como o acesso às tecnologias, o que no fundo revela-se é a diferença que as atitudes e habilidades para o uso da informação podem fazer na vida dos sujeitos e da comunidade em que vivem.

Não obstante, em narrativas, o próprio professor possa ter manifestado as suas limitações em relação ao uso das tecnologias, também afirmam que Ihe são oferecidos mecanismos de aprimoramento ao universo tecnológico e informacional, procurando replicar tais atitudes em sala de aula. Esses mecanismos são possíveis em virtude da forte atuação política da OEI que prevê parcerias com empresas de diversas naturezas, ministérios e secretarias de educação, como no caso do Uruguai, com o Plan Ceibal.

Em avaliação externa contratada pela OEI em relação ao projeto Luces para Aprender, uma das recomendações é: "Profundizar y reforzar el desarrollo de la red de docentes Luces para Aprender como instrumento eficaz en futuros programas de mejora de la calidad y equidad educativa." (OEI, 2018b, p. 10). Os profissionais da informação, em especial os bibliotecários, devem ficar atentos e procurar fazer parte desta rede, pois sabe-se da importância no estabelecimento de programas de competência em informação no âmbito escolar, consolidandoos em políticas públicas. Tais profissionais não podem omitir-se, e ficar à espera de que a OEI - salvo e se por sorte tiver alguém na equipe que comungue tal ideia - vá sistematizar o processo de competência em informação em suas políticas.

Que é preciso ter acesso à informação, dominar tecnologias, desenvolver sujeitos críticos, dentre outras ações, já é de conhecimento dos profissionais de áreas como a Ciência da Informação e Biblioteconomia, no entanto, precisa haver um posicionamento desses mesmos profissionais, com o objetivo de pleitear ações permanentes, contínuas e eficazes para que a sociedade da informação - que agora abre-se para escolas de área rural possam despertar para que o ser competente em informação pode ser um diferencial na vida da comunidade e na sua própria.

Outra pesquisa para investigar o desenvolvimento de habilidades informacionais, nas comunidades contempladas com o LPA, seria indicada. E a partir daí, trabalhar a criação de políticas públicas com a provisão de programas que desenvolvam a competência em informação, em comunidades específicas, como as de áreas rurais, ao menos identificadas como vulneráveis em vários aspectos.

A OEI como um Organismo que investe fortemente na educação e no acesso de pessoas vulneráveis na sociedade da informação, poderia levar em conta propostas de programas envolvendo a competência em 
informação, já que vislumbram-se discursos que conectam-se com os princípios das dimensões técnica, estética, ética e política da competência em informação, embora não haja uma sistematização de tal, nem em nível administrativo, nem nas práticas pedagógicas.

Para a concretização do que se propõe, baseamo-nos em Belluzzo (2008) que afirma haver necessidade de trabalho conjunto entre educadores e bibliotecários, objetivando:

Preparação de diretrizes básicas para iniciativas conjuntas sob o enfoque das necessidades da sociedade da informação e dos princípios da Competência em informação, uma atividade intra-curricular. Defininir as condições para que tais iniciativas possam ser apoiadas por políticas e pelas comunidades assistidas. Implementar e criar mecanismos de manutenção e avaliação das práticas pedagógicas e informacionais.(BELLUZZO, 2008, p. 13).

Cursos e profissionais envolvidos diretamente com a pesquisa sobre competência em informação podem e devem contribuir com projetos como Luces para Aprender, auxiliando para que recursos e estruturas sejam aproveitadas ao máximo. Afinal, realiza-se num ambiente de educação, conta com elementos, como professores, alunos, gestores, com a proposta de levar a tecnologia, e embora não sistematizado, apresentou conexões com as quatro dimensões da competência da informação, divulgadas por Vitorino e Piantola (2011), que são a técnica, estética, ética e política.

Mais do que estudar a competência em informação em contexto educacional, por meio de uma Organização voltada a políticas públicas para a educação, pretendeu-se fazê-lo em um cenário em que a vulnerabilidade apresenta-se pulsante, em minorias que vivem à margem do conforto e de facilidades. Por isso, a competência em informação foi analisada como um processo e fenômeno capaz de trazer transformações sociais mais amplas a essas comunidades, procurando refletir até que ponto a educação tem oportunizado aos sujeitos dessas regiões o desenvolvimento da competência em informação e a construção do conhecimento e aprendizagem ao longo da vida.

\section{Referências}

ABBAGNANO, N. Dicionário de filosofia. 5. ed. São Paulo: Martins Fontes, 2007. xiv, 1210 p.

ARAGÃO. A. Prevenção de riscos na União Europeia: o dever de tomar em consideração a vulnerabilidade social para uma protecção civil eficaz e justa. Revista Crítica de Ciências Sociais. Coimbra, n. 93. Quadrimestral, 2011. Disponível em: http://rccs.revues.org/174. Acesso em: 06 jan. 2019.

BAWDEN, D. Revisión de los conceptos de alfabetización informacional y alfabetización digital. Anales de documentación, Murcia, Espanha, v. 5, p. 361-408, 2002. Disponível em: http://revistas.um.es/analesdoc/article/view/2261/2251. Acesso em 28 jun. 2018. [Tradução de Fernández Toledo y José A. Gómez Hernández do original: Information and digital literacy: a review of concepts].

BELLUZZO, R. C. B. A competência em informação no Brasil: cenários e espectros. São Paulo: ABECIN, 2018. Disponível em: http://abecin.org.br/data/documents/E-Book Belluzzo.pdf. Acesso em: 03 jan. 2019. (livro digital)

BELLUZZO, R. C. B.; FERES, G. G. Competência em informação, redes de conhecimento e as metas educativas para 2021: reflexões e inter-relações. In.: BELLUZZO, R. C. B.; FERES, G. G.; VALENTIM, M. L. P (Org.). Redes de conhecimento e competência em informação: interfaces da gestão, mediação e uso da informação. Rio de Janeiro : Interciência, 2015. p. 135.

BELLUZZO, R. C. B.; SANTOS, C. A.; ALMEIDA JUNIOR, O. F. A Competência em informação e sua avaliação sob a ótica da mediação da informação: reflexões e aproximações teóricas. Informação \& Informação, Londrina, PR, v. 19, n. 2, p. 60-77, maio/ago. 2014. Disponível em: http://www.uel.br/revistas/uel/index.php/informacao/article/view/19995/pdf 21. Acesso em: 03 jan. 2019

BUSSO, G. Vulnerabilidad social: nociones e implicancias de políticas para latinoamerica a inicios del siglo xxi. In: SEMINÁRIO INTERNACIONAL LAS DIFERENTES EXPRESIONES DE LA VULNERABILIDAD SOCIAL EN AMÉRICA LATINA Y EL CARIBE, 2001, Santiago de Chile. Disponível em: http://www.cepal.org/publicaciones/xml/3/8283/Gbusso.pdf. Acesso em: 03 jan. 2019.

GOMES, H. F. A dimensão dialógica, estética, formativa e ética da mediação da informação. Inf. Inf., Londrina, v. 19, n. 2, p. 46-59, maio/ago. 2014. Disponível em: http://www.uel.br/revistas/uel/index.php/informacao/article/view/19994/19090. Acesso em: 08 jan. 2019. 
HIGH-LEVEL Colloquium on Information Literacy and Lifelong Learning Final Report. Alexandria: UNESCO/NFIL/IFLA, 2006. Disponível em: https://www. ifla.org/files/assets/information-literacy/publications/high-level-colloquium-2005.pdf. Acesso em: 03 jan. 2019

INTERNATIONAL FEDERATION OF LIBRARY ASSOCIATIONS AND INSTITUTIONS (IFLA). Lyon Declaration on Access to Information and Development. Haia, 2014. Disponível em: http://www.lyondeclaration.org/content/pages/lyondeclaration.pdf. Acesso em: 03 jan. 2019.

MARANDOLA JR., E. Uma antologia geográfica dos riscos: duas escalas, três dimensões. Geografia, Rio Claro, v. 29. n. 3. p. 315-338, set./dez. 2004. Disponível em: https://fenomenologiaegeografia.files.wordpress.com/2014/06/uma-ontologiageogrc3a1fica-dos-riscos-marandola-ir.pdf. Acesso em: 06 jan. 2019.

MARANDOLA JUNIOR., E.; HOGAN, D. J. As dimensões da vulnerabilidade. São Paulo em Perspectiva, v. 20, n. 1, p. 33-43, jan./mar. 2006. Disponível em: http://produtos.seade.gov.br/produtos/spp/v20n01/v20n01 03.pdf. Acesso em: 03 jan. 2019.

MARTINS, H. H. T. S. Metodologia qualitativa de pesquisa. Educação e Pesquisa, São Paulo, v.30, n.2, p. 289-300, maio/ago. 2004. Disponível em: http://www.scielo.br/pdf/ep/v30n2/v30n2a07.pdf. Acesso em: 03 jan. 2019.

MARTINS, H. H. T. S. O ensino de métodos e técnicas de pesquisa nos cursos de Ciências Sociais. Cronos, Natal, RN, v. 8 , n. 2, p. 387-394, jul./dez. 2007. Disponível em: file:///C:/Users/T\%C3\%A2nia/Downloads/1840-Texto\%20do\%20artigo-5408-110-20120512.pdf. Acesso em: 03 jan. 2019.

MUYLAERT et al. Entrevistas narrativas: um importante recurso em pesquisa qualitativa. Rev. Esc. Enferm., São Paulo, v. 48 , n. esp. 2, 2014. Disponível em: http://www.scielo.br/pdf/reeusp/v48nspe2/pt 0080-6234-reeusp-48-nspe2-00184.pdf. Acesso em: 07 jan. 2019

ORGANIZACIÓN DE ESTADOS IBEROAMERICANOS PARA LA EDUCACIÓN, LA CIENCIA Y LA CULTURA (OEI). A Organização de Estados Ibero-americanos para a Educação, a Ciência e a Cultura e a educação ao longo da vida. In: Seminário "Política Brasileira de Educação ao Longo da Vida". Porto Seguro, 16 a 18 de setembro de 2015. OEI, 2015. Disponível em:

http://forumeja.org.br/sites/forumeja.org.br/files/estados ibero americanos educa\%C3\%A7ao ciencia cultura educacao.pdf. Acesso em: 05 jan. 2019.

ORGANIZACIÓN DE ESTADOS IBEROAMERICANOS PARA LA EDUCACIÓN, LA CIENCIA Y LA CULTURA (OEI). Educação ao longo da vida. In: [Folheto-OEI-2017.POR]. Madri: OEI, 2017. Disponível em: https://www.oei.bo/assets/files/Folleto-OEl-2017.POR.pdf. Acesso em: 05 jan. 2019.

ORGANIZACIÓN DE ESTADOS IBEROAMERICANOS PARA LA EDUCACIÓN, LA CIENCIA Y LA CULTURA (OEI). Luces para aprender: Madri: OEI, [2013?]. Disponível em: https://www.oei.es/historico/xxiii/cie/luces.pdf. Acesso em: 05 jan. 2019.

ORGANIZACIÓN DE ESTADOS IBEROAMERICANOS PARA LA EDUCACIÓN, LA CIENCIA Y LA CULTURA (OEI) Luces para aprender. Informe de evalucación de impacto. Anexo 6: resumen ejecutivo. Madri: OEl, 2018. 09 p. Disponível em: https://www.oei.es/uploads/files/.../8/41/resumen-ejecutivo.pdf. Acesso em: 08 jan. 2019.

ORGANIZACIÓN DE ESTADOS IBEROAMERICANOS PARA LA EDUCACIÓN, LA CIENCIA Y LA CULTURA (OEI). Metas educativas 2021: la educación que queremos para la generación de los bicentenarios: documento final. Madrid: OEI, 2010. 281 p. Disponível em: http://www.oei.es/metas2021.pdf. Acesso em: 05 jan. 2019.

ORGANIZACIÓN DE ESTADOS IBEROAMERICANOS PARA LA EDUCACIÓN, LA CIENCIA Y LA CULTURA (OEI). Miradas sobre la educación em lberoamérica: educación de los pueblos y comunidades indígenas (originarios) y afrodescendientes. Madri: OEI, 2015b. Disponível em: http://www.oei.es/miradas2015/Miradas2015.pdf. Acesso em: 05 jan. 2019.

ORGANIZACIÓN DE ESTADOS IBEROAMERICANOS PARA LA EDUCACIÓN, LA CIENCIA Y LA CULTURA (OEI). PIan Iberoamericano de Alfabetización y Aprendizaje a lo largo de la Vida 2015-2021. In: XXIV Conferencia lberoamericana de Ministros de Educación. Ciudad de México, 28 de agosto de 2014. OEl, 2014. Disponível em: https://www.oei.es/historico/xxivcie/PIA.pdf. Acesso em: 07 jan. 2019.

ORGANIZACIÓN DE ESTADOS IBEROAMERICANOS PARA LA EDUCACIÓN, LA CIENCIA Y LA CULTURA (OEI). Que es Ia OEI. Madri: OEI, [2017]. Disponível em: http://www.oei.es/acercade/que-es-la-oei. Acesso em: 05 jan. 2019.

PLAN CEIBAL. Qué es Plan Ceibal. Montevidéu, Uruguai, 2018. Disponível em: https://www.ceibal.edu.uy/es/institucional. Acesso em: 08 jan. 2019.

RIGHETTO, G. G.; VITORINO, E. V.; MURIEL-TORRADO, H. Competência em informação no contexto da vulnerabilidade social: conexões possíveis. Inf. \& Soc.: Est., João Pessoa, v. 28, n.1, p. 77-90, jan./abr. 2018. Disponível em: http://www. periodicos.ufpb.br/ojs2/index.php/ies/article/viewFile/34735/pdf. Acesso em: 08 jan. 2019. 
SILVA, E. et al. Origem, características e classificação das organizações internacionais. Rev. do Mestr. em Direito da UCB, Brasília, DF, v. 1, n. 2, p. 147-162, jul./dez. 2007. Disponível em:

https://portalrevistas.ucb.br/index.php/rvmd/article/view/2609/1599. Acesso em: 07 jan. 2019.

SOKOLOWSKI, R. Introdução à fenomenologia. São Paulo: Ed. Loyola, 2004. 247 p.

THYWISSEN, K. Components of risk: a comparative glossary. Alemanha: UNU-EHS, 2006. Disponível em: http://collections.unu.edu/eserv/unu:1869/pdf4042.pdf. Acesso em: 06 jan. 2019.

TWIGG, J. Sustainable livelihoods and vulnerability to disasters. Benfield Greig Hazard Research Centre, Disaster Management Working Paper n. 2, 2001. Disponível em: https://www.ucl.ac.uk/hazardcentre/resources/working papers/working papers folder/wp2. Acesso em: 03 jan. 2019.

VITORINO, E. V. Análise dimensional da competência em informação: bases teóricas e conceituais para reflexão. RICl: R.Ibero-amer. Ci. Inf., Brasília, v. 9, n. 2, p. 421-440, jul./ dez. 2016. Disponível em: https://periodicos.unb.br/index.php/RICl/article/view/2420/2159. Acesso em: 06 jan. 2019.

VITORINO, E. V. A competência em informação e a vulnerabilidade: construindo sentidos à temática da "vulnerabilidade em informação". Ci.Inf., Brasília, DF, v.47 n.2, p.71-85, maio/ago. 2018. Disponível em: http://revista.ibict.br/ciinf/article/view/4187/3794. Acesso em: 03 jan. 2019.

VITORINO, E. V.; PIANTOLA, D. Dimensões da Competência informacional. Ci Inf., Brasília, DF, v. 40, n. 1, p. 99-110, jan./abr. 2011. Disponível em: http://revista.ibict.br/clinf/index.php/ciinf/article/view/1918/1397. Acesso em: 05 jan. 2019.

ZURKOWSKI, P. G. Information services environment relationships and priorities. Washington D.C.: National Commission on Libraries, 1974. Disponível em: http://www.eric.ed.gov/PDFS/ED100391.pdf. Acesso em: 03 jan. 2019.

WELLER, W.; ZARDO, S. P. Entrevista narrativa com especilistas: aportes metodológicos e exemplificação. Revista da FAEEBA - Educação e Contemporaneidade, Salvador, v. 22, n. 40, p. 131-143, jul./dez. 2013. Disponível em: http://www.revistas.uneb.br/index.php/faeeba/article/view/757/530. Acesso em: 03 jan. 2019.

\section{Dados dos autores}

Tânia Regina de Brito

Mestra em Ciência da Informação pela Universidade Federal de Santa Catarina (UFSC). Doutoranda em Ciência da Informação na Universidade Estadual Paulista "Júlio de Mesquita Filho". Bibliotecária-Documentalista da Universidade Federal de Mato Grosso do Sul.

taniacgms@gmail.com

\section{Elizete Vieira Vitorino}

Doutora e Mestre em Engenharia de Produção pela Universidade Federal de Santa Catarina (UFSC). Professora no Departamento de Ciência da Informação (CIN), do Centro de Ciências da Educação (CED) da Universidade Federal de Santa Catarina (UFSC). Atua nos Cursos de Graduação em Arquivologia, Biblioteconomia e Ciência da Informação, e no Programa de Pós-Graduação em Ciência da Informação (PGCIN).

elizete.vitorino@ufsc.br

Received - Recebido: 2019-02-07

Accepted - Aceitado: 2020-10-24

\section{(cc) EY}

This work is licensed under a Creative Commons Attribution 4.0 United States License.

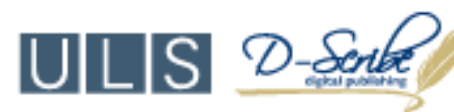

This journal is published by the University Library System of the University of Pittsburgh as part of its D-Scribe Digital Publishing Program and is cosponsored by the University of Pittsburgh Press. 